Special issue of the 3rd International Conference on Computational and Experimental Science and Engineering (ICCESEN 2016)

\title{
Effect of Double Stage Nitriding on 34CrAlNi7-10 Nitriding Steel
}

\author{
İ. Altinsoy ${ }^{a}$, G.F. Çelebi Efe ${ }^{a}$, T. $\operatorname{YeneR}^{a}$, K.G. Önder ${ }^{b}$ And C. Bindal ${ }^{a *}$ \\ ${ }^{a}$ Sakarya University, Department of Metallurgical and Material Engineering, Sakarya, Turkey \\ ${ }^{b}$ Mikrosan Makina ve Kalıp San. A.S. Heat Treatment Department, Izmit, Kocaelı
}

\begin{abstract}
In this study, effect of double stage gas nitriding of $34 \mathrm{CrAlNi7-10}$ steel was analyzed. Nitriding processes were carried out in two stages. in the first stage, samples were nitridied at $500{ }^{\circ} \mathrm{C}$ for $10 \mathrm{~h}$ and then in second stage nitriding process was continued at 530 and $550^{\circ} \mathrm{C}$ for $20 \mathrm{~h}$. During both stages, the nitrogen activity on surface was controlled by the nitriding potential, which is a thermodynamical control parameter for controlled gas nitriding process. The nitriding potential was kept constant, at value of 10, during the first stage and was varied in the range of 3.2-0.2, for both nitriding temperatures, in the second stage. The presence of nitrides, formed on the surface of test materials was determined by XRD analysis technique. The morphology of nitrided layer was studied by optical microscopy. The microhardness of the surfaces of nitrided samples in HV1 was between 955 and 1029. The measurements have shown that the thickness of the compound layer (white layer) has varied between $6.85-23.90 \mu \mathrm{m}$ and that the growth of the white layer and microhardness gradient were strongly affected by the nitriding potential and the temperature. Diffusion depths as Nht(HV) for Vickers Hardness were determined and compared.
\end{abstract}

DOI: 10.12693/APhysPolA.132.663

PACS/topics: 81.05.BX, 81.65.LP, 81.70.BT

\section{Introduction}

Various surface treatment methods, aimed at improving wear and corrosion resistance, and mechanical properties of alloys are described in many recent reports [1]. Gas nitriding (GN) is a thermochemical surface treatment, which has been widely used for components made of steel, to improve the surface hardness, corrosion and wear resistance [2-4]. In recent years, GN has become one of the most widely used surface engineering techniques, owing to its simple operation and excellent applicability to a wide range of steel grades, as well as due to the small dimensional changes of nitrided workpieces [2].

The control of the process, using the thermodynamical parameter $K_{N}$, gives the ability to produce hardened layers with variable metallurgical properties. It is possible to produce parts with improved surface properties and prolonged working life, as a result of nitriding under right process parameters and proper material selection, by taking into account the properties of operating environment, operating conditions and the mechanical requirements for the surface [5].

Time and temperature are the main factors, which determine the hardness profile on nitrided steels with a given composition [6]. The nitriding may be accomplished by either a single-stage or double-stage process. In the single-range process, the brittle gamma iron nitride is produced at temperatures in the range of about 500 to $525{ }^{\circ} \mathrm{C}$. The dissociation rate of ammonia ranges from 15 to $30 \%$.

*corresponding author; e-mail: bindal@sakarya.edu.tr
The double-stage process is known as the Floe process. The first stage of the double-stage process is the same as the single-stage process. The principal purpose of the second stage is to minimize the depth of the white layer. The dissociation rate of ammonia is increased to $65-85 \%$ with the temperature ranging from 550 to $565^{\circ} \mathrm{C}$. Since the $\mathrm{NH}_{3}$ content of the atmosphere is reduced, the iron nitride does not grow as rapidly, and in fact dissolves, as it supplies nitrogen into the interior of the steel. Nitriding times are quite long, anywhere from 10 to $130 \mathrm{~h}$, depending on the application, and the case depths are relatively shallow [7].

$34 \mathrm{CrAlNi} 7$ is $\mathrm{Cr}-\mathrm{Al}-\mathrm{Ni}$ alloyed industrial nitriding steel, widely used in manufacturing of machine elements, where the high surface hardness and improved wear resistance are required. Binary and ternary alloys have been the subject of many investigations, which showed that aluminium and chromium increase the nitrogen content and the hardness, due to the chromium nitrides FCC semi-coherent precipitation [8]. Under such conditions, the structure of the nitrided layers is such that the top nitride layer, known as the compound layer, is composed mainly of $\gamma^{\prime}-\mathrm{Fe}_{4} \mathrm{~N}$ and $\varepsilon-\mathrm{Fe}_{2-3} \mathrm{~N}$, as well as nitrides of alloying elements, as with aluminium-enriched $\gamma^{\prime}$-phase of $(\mathrm{Fe}, \mathrm{Al})_{4} \mathrm{~N}$, which lies below the $\varepsilon$-phase and penetrates into the depth of the metal, along the grain boundaries. The layer beneath the compound layer is known as the so-called diffusion layer, which consists mainly of interstitial atoms in solid solution and fine, coherent nitride precipitates, when the solubility limit is reached $[9,10]$.

The aim of the present study is to investigate the effect of the nitriding parameters, as well as the effect of the nitriding method on some properties of nitrided zone of the samples. 


\section{Experimental study}

In this study, gas nitriding processes for the $34 \mathrm{CrAlNi} 7$ nitriding steels were performed via $K_{N}$-controlled gas nitriding method in two stages. Firstly, steel samples were nitrided at $500{ }^{\circ} \mathrm{C}$ for 10 hours, followed by the second stage nitriding at 530 and $550^{\circ} \mathrm{C}$, respectively for $20 \mathrm{~h}$. $K_{N 1}$ nitriding potentials were selected to be $10 \mathrm{~atm}^{-1 / 2}$ for the first stage, and in the latter stage, $K_{N 2}$ values were adjusted between 0.2 and $3.2 \mathrm{~atm}^{-1 / 2}$, to ensure a certain form of iron nitride $\left(\mathrm{Fe}_{2-3} \mathrm{~N}\right.$ or $\left.\mathrm{Fe}_{4} \mathrm{~N}\right)$ to be formed on the surface of the substrate by using Lehrer diagram (Fig. 1) [11]. The depth of nitriding zones was determined by measuring microhardness at the diffusion zone. Surface hardness was measured using HV hardness method.

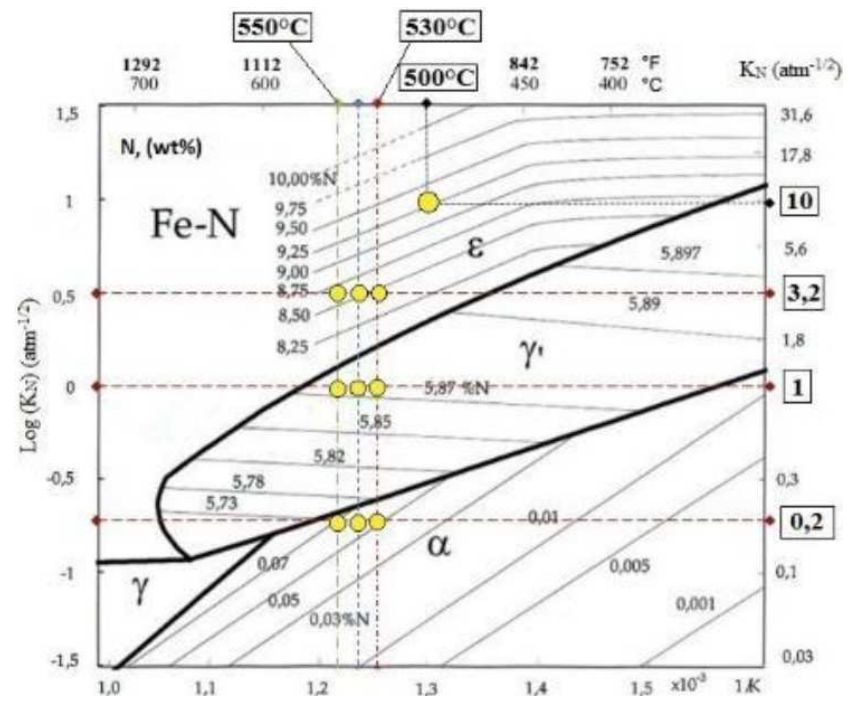

Fig. 1. Representation of gas nitriding parameters on Lehrer diagram [11].

The microstructures of the nitrided zone were examined using light-metal microscope and the thickness of the white layer and of the diffusion zones were measured using Clemex software. The phases formed on the nitrided surfaces and in the white layer were determined by $\mathrm{XRD}$ analysis, using $\mathrm{Cr}-\mathrm{K}_{\alpha}$ radiation.

\section{Results and discussion}

Optical micrographs of nitrided zones revealed that the growth of white layer was strongly affected by $K_{N 2}$ values. White layer became thicker with the increasing temperature of second stage nitriding for constant $K_{N 2}$ value. Decreasing of $K_{N 2}$ values caused formation of thinner white layer at constant temperature of second stage nitriding. Aluminium within the samples promotes intercrystalline diffusion of nitrogen and alloys the $\gamma^{\prime}$-phase $\left(\mathrm{Fe}_{4} \mathrm{~N}\right)$ in form of $(\mathrm{Fe}, \mathrm{Al})_{4} \mathrm{~N} . \gamma^{\prime}$ phase grows preferentially in the "whiskers" forming through the grain boundaries (Table I) [9, 12].

\section{TABLE I}

Optical microscope images of the double stage gas nitrided $34 \mathrm{CrAlNi} 7$ samples, processed at different temperatures and using different $K_{N 2}$ parameters, for $20 \mathrm{~h}$, after the first nitriding stage, conducted at $500{ }^{\circ} \mathrm{C}$ and $K_{N 1}=10$ for $10 \mathrm{~h}(500 \times)$.

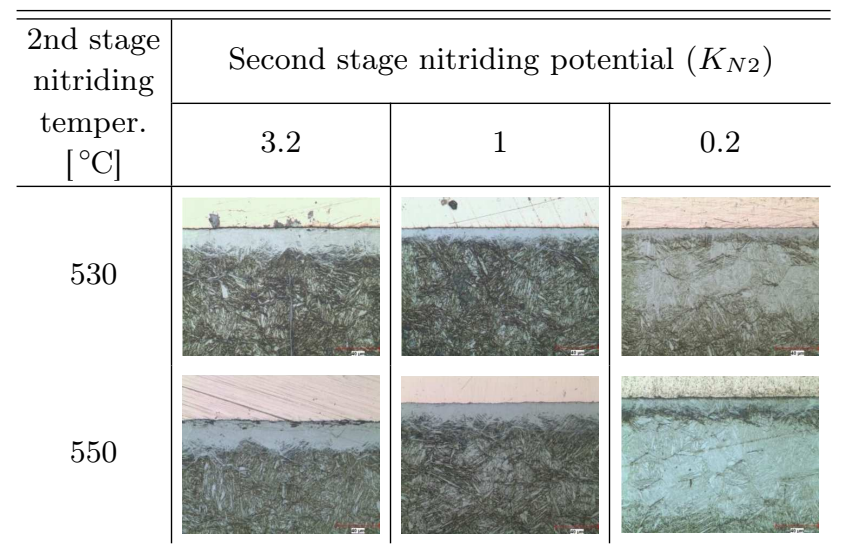

Figure 2 shows the XRD patterns of the samples, gas nitrided at $500{ }^{\circ} \mathrm{C}$ and $550{ }^{\circ} \mathrm{C}$ in the second stage for $20 \mathrm{~h}$. There are $\alpha, \varepsilon$ and $\gamma^{\prime}$ peaks in the XRD patterns, which show that the compound layer consists of $\varepsilon-\gamma^{\prime}$ nitride phases, occurring together in a bilayer structure, while $\alpha$ corresponds to iron phase of the steel samples. It was determined from the XRD patterns that the intensity of $\varepsilon$ peaks has decreased, while the intensity of $\gamma^{\prime}$ peaks has increased with the decrease of $K_{N 2}$ values from 3.2 to 0.2 . This indicates on the increasing ratio of $\gamma^{\prime} / \varepsilon$ phases within the white layer (Fig. 2).

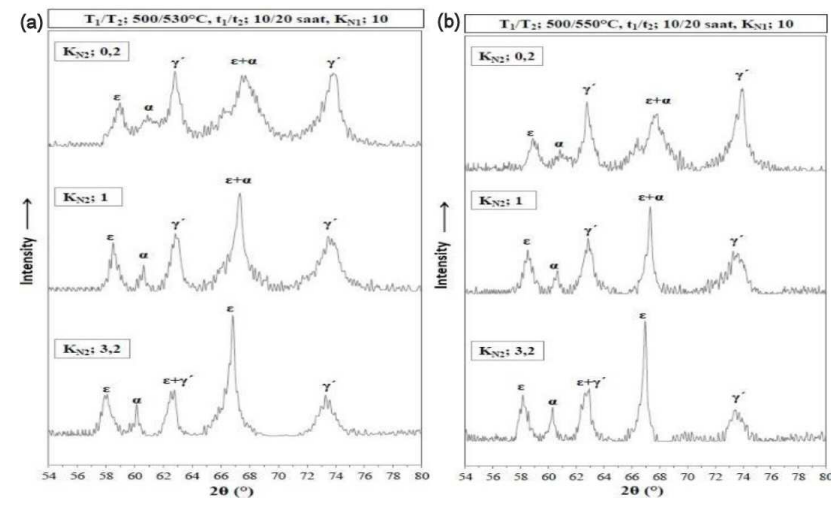

Fig. 2. XRD patterns of double stage gas nitrided samples, nitrided at (a) $530{ }^{\circ} \mathrm{C}$ and (b) $550{ }^{\circ} \mathrm{C}$.

Average results of the measurements for compound layers are showed in Fig. 3. The thickness of the white layer, formed on 34CrAlNi7-10 steel samples, was strongly affected by the change of $K_{N 2}$ values at both second stage nitriding temperatures. As a result of decreasing second stage nitriding temperatures and $K_{N 2}$ parameters, the thickness of the white layer has remarkably declined (the initial thickness of white layer after the first nitriding stage, conducted at $500^{\circ} \mathrm{C}$ and $K_{N 1}$ value of 10 for $10 \mathrm{~h}$ was measured as $8.54 \mu \mathrm{m}$ ) (Fig. 3). 


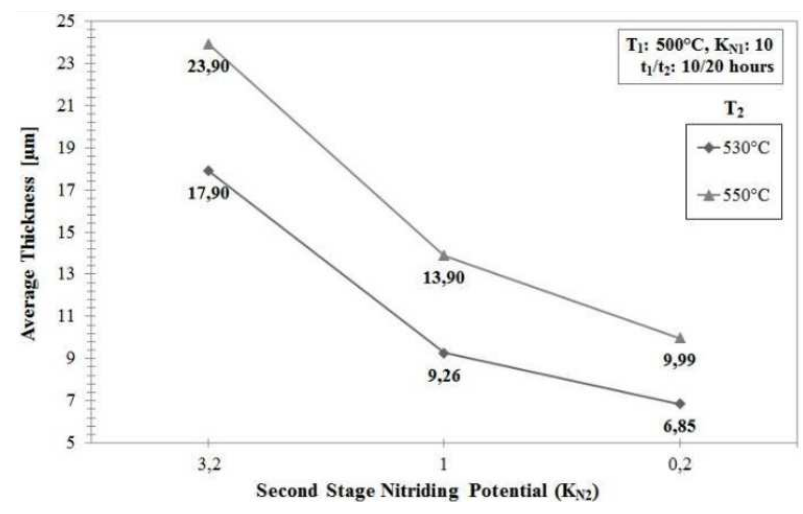

Fig. 3. Variation of white layer thickness in double stage gas nitrided $34 \mathrm{CrAlNi} 7$ steel.

Figure 4 shows the effect of second stage nitriding temperatures and $K_{N 2}$ values on the depth of the effective hardness. The diffusion depth has increased with increasing second stage nitriding temperature, while it has decreased with the decrease of the $K_{N 2}$ parameter. The results are consistent with the literature and the diffusion equations. Increasing temperature provides more atomic nitrogen diffusing towards the core, by raising the diffusion coefficient of nitrogen. On the other hand, decreasing $K_{N 2}$ parameter has the inverse effect on the diffusion rates of the nitrogen (Fig. 4).

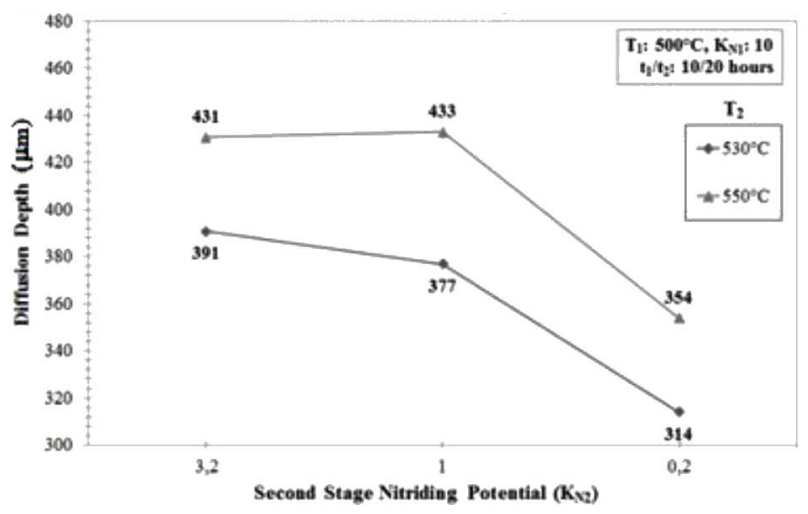

Fig. 4. Effect of second stage nitriding temperature and $K_{N 2}$ parameter on the effective hardness depth (Nht Core Hardness+50 HV) of 34CrAlNi7 steel.

The microhardness values, measured on the surface of the samples, have decreased with the increasing process temperature for all $K_{N 2}$ values. Because of the fact that the increase in the white layer thickness makes the compound layer more brittle, the $\mathrm{HV}_{1}$ hardness decreases in addition to the increase of brittleness. However, microhardness of the white layer has slightly increased with the decrease of $K_{N 2}$ value from 3.2 to 1, while the microhardness has decreased for both second stage nitriding temperatures at lower $K_{N 2}$ values $\left(K_{N 2}=0.2\right)$. This has probably resulted from the optimum toughness of the white layer, obtained at $K_{N 2}$ of 1 , by possibly attaining the best $\gamma^{\prime} / \varepsilon$ ratio in the compound layer (see Fig. 2). On the other hand, smaller values of the $K_{N 2}$ parameter have caused very thin white layer and thus, hardness values could correspond to both, the compound and the diffusion layer (Fig. 5).

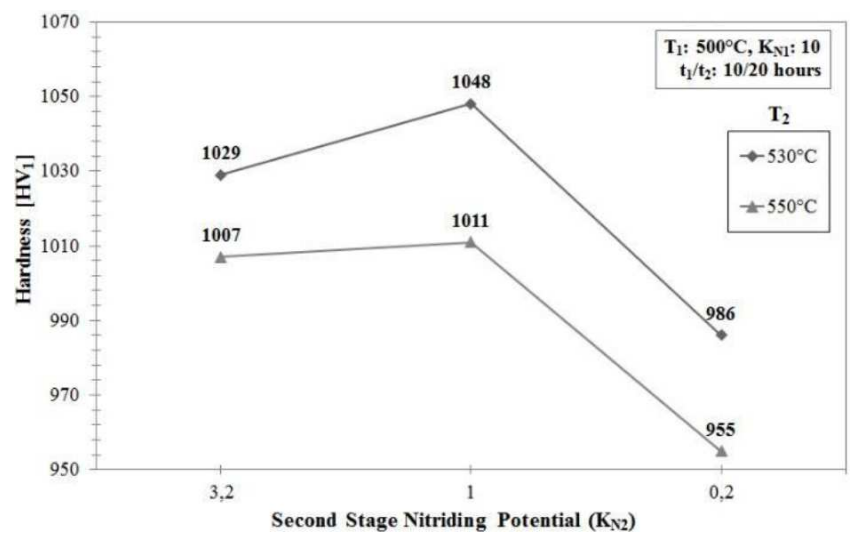

Fig. 5. Variation of surface hardness in double stage gas nitrided $34 \mathrm{CrAlNi} 7$ steel.

\section{Conclusions}

In the summary of this study, the following results were obtained;

- Optical micrographs of the nitrided zones have revealed that white layer became thicker with increasing second stage nitriding temperature, for constant $\mathrm{K}_{N 2}$ value and that decreasing of $K_{N 2}$ values has caused formation of thinner white layer, at constant second stage nitriding temperature.

- XRD analysis has shown that the compound layer consists of $\varepsilon-\gamma^{\prime}$ nitride phases, occurring together in a bilayer structure. The intensity of $\varepsilon$ peaks has decreased, while the intensity of $\gamma^{\prime}$ peaks has increased with the decrease of $K_{N 2}$ values from 3.2 to 0.2 .

- The thickness of the white layer has remarkably declined with decreasing both, the second stage nitriding temperatures and the $K_{N 2}$ parameters.

- The diffusion depth has increased by increasing second stage nitriding temperature, while it has decreased with the decrease of $K_{N 2}$ parameter.

- The microhardness values of the samples have decreased with increasing process temperature for all $K_{N 2}$ values. On the other hand, microhardness of the white layer has slightly increased with the decrease of $K_{N 2}$ value from 3.2 to 1 , while the microhardness has decreased at lower $K_{N 2}$ values $\left(K_{N 2}=0.2\right)$. 


\section{References}

[1] N. Ucar, N. Turku, A.F. Ozdemir, A. Calik, Acta Phys. Pol. A 130, 492 (2016).

[2] B. Wang, W. Fu, F. Dong, G. Jin, W. Feng, Z. Wang, S. Sun, Mater. Design 85, 91 (2015).

[3] B. Wang, S. Sun, M. Guo, G. Jin, Z. Zhou, W. Fu, Surf. Coat. Technol. 279, 60 (2015).

[4] N. Syla, F. Aliaja, B. Dalipi, Acta Phys. Pol. A 130, 83 (2016).

[5] K. Onder, M.Sc. Thesis, Sakarya Universitesi, 2013.

[6] R. Schneider, H. Hiebler, J. Mater. Sc. 33, 1737 (1998).

[7] W. Liu, M.Sc. Thesis, Worcester Polytechnic Institute, 2008.
[8] C. Ginter, L. Torchane, J. Dulcy, M. Gantois, A Malchere, C. Esnouf, T. Turpin, La Metallurgia Italiana 7-8, 29 (2006).

[9] Y. Lakhtin, Metal Sci. Heat Treat. 38, 6 (1996).

[10] O. Ozturk, O. Onmus, D.L. Williamson, Surf. Coat. Technol. 196, 341 (2005).

[11] M. Korwin, W. Liliental, L. Maldzinski, A. Czelusniak, G. Tymowski, Nitreg Controlled Gas Nitriding. An Environment-Friendly Process for Surface Hardening of Steel, Nitrex Metal, Canada 1999.

[12] Y. Lakhtin, N. Silina, V. Fedchun, Metal Sci. Heat Treat. 23, 162 (1981) 